\title{
Correspondence
}

\section{PhDs: adapt training for developing world}

Paula Stephan condemns the expansion of $\mathrm{PhD}$ programmes in the face of "almost no career prospects" (Nature 484, 29-31; 2012). As a mentor of African clinicians undergoing $\mathrm{PhD}$ training, I can vouch for the academic rewards that a $\mathrm{PhD}$ delivers in developing countries. These include appointments to faculty positions and international grant awards.

African universities are asking for support in developing $\mathrm{PhD}$ programmes to train researchers who can address Africa's myriad problems. To optimize the value of these efforts, they must concentrate on the domains that need most attention and consider the most appropriate type and content of $\mathrm{PhD}$ training. Requirements for mentoring, evaluating progress and meeting international standards also need to be set.

Robert Colebunders Institute of Tropical Medicine and University of Antwerp, Belgium. bcoleb@itg.be

\section{PhDs: acquired skills good for marketplace}

Paula Stephan argues that $\mathrm{PhD}$ programmes deliver low returns to the taxpayer because career prospects are poor (Nature 484, $29-31 ; 2012$ ). But at less than $2 \%$, the rate of unemployment for $\mathrm{PhDs}$ in the United States is lower than for the general population.

Any highly educated person will be attractive to employers, particularly if that individual has experience in project management, data analysis and effective communication. Jobs in areas such as biomedical research are hard to obtain, but can be found in academia, industry and government. Rewarding careers for $\mathrm{PhDs}$ also exist in publishing, intellectual property, science education, conservation and research administration. Thanks to research grants and stipends, most US graduates will enter the job market with little or no debt.

Much university research is conducted by faculty members and students, rather than by permanent research staff, so new knowledge that could benefit society comes at a relatively low cost to taxpayers.

As with law or medical schools, $\mathrm{PhD}$ programmes produce many more graduates than are needed to replace faculty advisers, so earning a $\mathrm{PhD}$ does not guarantee a permanent position in either academia or industry. New PhDs face risks, but risktakers often turn out to be the most innovative investigators. Henrik G. Dohlman University of North Carolina, Chapel Hill, USA. henrik_dohlman@med.unc.edu

\section{No silver bullets for African soil problems}

Conservation agriculture is being used increasingly around the world (H. Buffett Nature 484, 455; 2012). But many of the claimed benefits of minimal or no-tillage farming - such as carbon sequestration and boosting crop yields - are far from proven (K.E. Giller et al. Field Crop Res. 124, 468-472; 2011).

Several of these conservation techniques are good agricultural practice: to sow with the first rains, to rotate crops, to fertilize them appropriately and to return crop residues to the soil. But in the absence of herbicides (a reality for many African smallholders), tillage can save labour, allows farmers to plant early and controls weeds. It helps to prevent runoff and erosion if the soil is not protected by mulch, for which smallholder farmers often lack the organic resources.

My view is therefore that an across-the-board recommendation of conservation agriculture is misplaced (Nature 483, 525-527; 2012). Given the enormous diversity of African smallholder farming systems, locally adapted, best-fit technologies are needed

(K. E. Giller et al. Agric. Syst. 104, 191-203; 2011).

Farming-systems analysis will identify for whom and where different intensification strategies are most likely to help. Ken E. Giller Plant Production Systems, Wageningen University, the Netherlands.

ken.giller@wur.nl

\section{Keep 'reproducibility' in context}

The call by Glenn Begley and Lee Ellis to raise standards in preclinical cancer research (Nature 483, 531-533; 2012) is an admirable piece of selfcritique that can be extended to all who study and treat human disease. Unfortunately, the kernel of their polemic - that reproducing published results can be problematic - was widely misinterpreted by the media.

The authors highlight an investigation in which scientific findings were confirmed in only 6 of 53 cases. This was picked up by news agencies, including Reuters, many of which construed the meaning as 'findings could not be replicated' — without mentioning the authors' nuanced caveats regarding the endpoints tested.

The public cannot be expected to appreciate the implications of, for example, a western blot working in one lab and not in another. Therefore, the meaning of 'reproducibility' in a particular context should be properly articulated. This could have prevented the mistaken inference that ' $90 \%$ of all science cannot be reproduced'.

In the complex data sets now being generated by genomics and proteomics, the nature of reproducibility is changing; it is increasingly dissimilar from that for more simple measurements. The basic meaning of scientific knowledge is shifting, and the community must learn to deal with it in ways that go beyond simple semantics.

Brad Picha OrthoIndy, Indianapolis, Indiana, USA. Matthew Thompson Abeon Medical, Brecksville, Ohio, USA. Thomas M. Vondriska David Geffen School of Medicine, University of California, Los Angeles, California, USA. tvondriska@mednet.ucla.edu

\section{EDITORIAL NOTE}

In their Comment article 'Raise standards for preclinical cancer research', C. Glenn Begley and Lee Ellis (Nature 483, 531-533; 2012) refer to scientists at Amgen who were able to reproduce findings in only $11 \%$ of 53 published papers. Several correspondents have asked for details of these studies, which were not provided in the article.

The Amgen scientists approached the papers' original authors to discuss findings and sometimes borrowed materials to repeat the experiments. In some cases, those authors required them to sign an agreement that they would not disclose their findings about specific papers. Begley and Ellis were therefore not free to identify the irreproducible papers - a fact that the Comment should have mentioned.

Nature, like most journals, requires authors of research papers to make their data available on request. In this less formal Comment, we chose not to enforce this requirement so that Begley and Ellis could abide by the legal agreements.

The scientists at Amgen could not have implemented their study had they reserved the right to reveal the outcome for individual papers. The Comment highlights important systemic problems in preclinical cancer research, which we felt appropriate to communicate to our readers, even though the authors could not disclose the studies in question. 